\title{
Janet Rossant
}

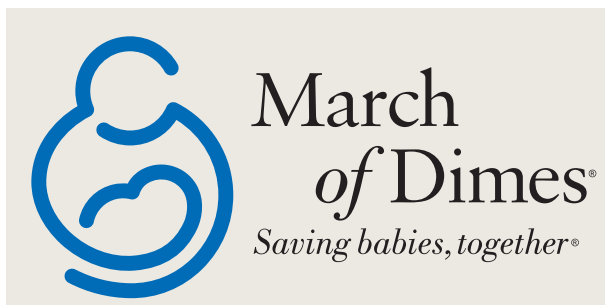

The March of Dimes Prize in Developmental Biology, a cash award of $\$ 250,000$ and a silver medal in the design of the Roosevelt dime, is awarded to investigators whose research has profoundly advanced the science that underlies our understanding of birth defects. This year the Prize goes jointly to Dr Janet Rossant from The Hospital for Sick Children in Toronto, Canada, and Dame Anne McLaren from The Gurdon Institute in Cambridge, UK, for their work on early mouse development. Magdalena Skipper talked to them to find out more about their work and to hear their opinions on new trends in developmental biology and emerging ethical issues. Below is an excerpt from a conversation with Dr Janet Rossant. An interview with Dame Anne McLaren will appear in the June issue of Nature Reviews Genetics.

The main focus of your work has been on early mouse development. Would you describe yourself as a cell biologist, geneticist, developmental biologist or are these labels, in fact, irrelevant?

I've largely thought of myself as a developmental biologist but these days these definitions become a little blurry. Because I use genetics as a tool to investigate development and explore genome manipulation to investigate all aspects of mouse biology I suppose I am a mouse geneticist too. And if one works on the early embryo one is going to be looking at the interactions between cells, how cells behave and talk to each other so I am also a cell biologist.

Your focus on mammalian development goes right back to your Ph.D. in Cambridge. Did you ever waver and think that other topics in biology might be even more fascinating? I still think that the problem of how a single cell, the egg, develops into a complex organism is incredibly fascinating. I know that of course there are those who think that the brain, and the understanding neural function and how we think and behave, is extremely fascinating, and indeed it is, but to me this is so complex that I wouldn't even know where to start. And the nice thing about development is that we do know where it begins [...] by focusing on some of the early stages when cells are making few decisions we might be able to get a handle on some of the later complexity.

You are the Director of the Centre for Modeling Human Disease. What do you see as the main limitations of using the mouse in this context? Could other models, zebrafish for example, complement the mouse in a significant way? Clearly, the mouse is not a human. [...] What is important is that although the individual alterations in the mouse might not give an identical phenotype to the human the pathways involved are usually the same. It's a two-way street - it's not that the mouse is an absolute model but it is a model in which you can look genetically at the whole pathway and use that to understand disease processes.

I do think that zebrafish complements the mouse but I wouldn't say it complements it in exploring human disease. As far as looking at specific similarities in complex diseases the mouse is still the best model because of the genetics. What zebrafish is fantastic for is the ability to explore in great detail the developmental pathways, particularly at the cellular level, because of the ability to see in the embryo how cells develop.

Mouse developmental genetics has seen a shift from research centred around one laboratory or institute to international, multicentre collaborative projects. You have experienced both - how do they compare?

I do do both and I actually enjoy both. The lab-based work, where you are working with individual students and postdocs on a daily basis, looking at intimate details of a particular pathway or event, looking down the microscope, seeing the embryos ... I think are very important. [...] Looking at the whole genome for its function is also extremely exciting because it opens whole new questions that you haven't even thought about. So you can take a particular process and dig down deep into it or you can stand back and say: look, there is a whole genome out there that we haven't explored yet; let's see if we can make mutations across the genome and find out what they do. I like both.

\section{With more and more genome sequences} becoming available and functional genomics approaches becoming more feasible in many species, is the role of model organisms set to diminish?

[Model organisms] are all somehow a little odd and not mainstream. [...] If we want to understand evolution through evo-devo studies we need to look at a broad range of species because we can't build out an evolutionary pathway by looking at extreme organisms. And it's extremely exciting to look at how differences in morphology and function across species actually can be plotted in the genome. But you're not going to be able to build out different organisms to the extent that you can experimentally manipulate them. We can get the genome, that can be done, but making an organism into an experimental organism takes a lot more work.

You were one of the authors of the recent ISSCR guidelines for human ES cell research. The international list of the authors reminds us that science transgresses political boundaries. Do you feel frustrated by countryspecific legislation on the use of human ES cells or are the regional differences justified? Science is a particularly international activity. When I look at my career, what's the most fun about it is that international flavour. The fact that science is a common language, and you can travel anywhere in the world, get off the plane and talk to someone and exchange ideas straight away. It is frustrating then when there are differences in the way that people can do science in different countries, especially in countries where the laws are more restrictive. This applies to all aspects of science but it is particularly obvious and public in the human ES cell debate. Having said that, the human ES cell debate is very complex because it touches on ethical and moral issues, opinions and beliefs that people hold very dear. So I do not think that we can expect that there would be one law, in fact if there was one law by definition it would be most restrictive. We really don't want that. 